\title{
Envolvimento orbitário difuso por displasia fibrosa na síndrome de McCune Albright: relato de caso
}

\author{
McCune Albright syndrome - diffuse orbital involvement due to fibrous \\ dysplasia: a case report
}

Márcio Alberto Costanzi ${ }^{1}$

Antonio Augusto Velascoe Cruz ${ }^{2}$
Trabalho realizado no Departamento de Oftalmologia, Otorrinolaringologia e Cirurgia de Cabeça e Pescoço da Faculdade de Medicina da Universidade de São Paulo - USP - Ribeirão Preto (SP) - Brasil.

Pós-graduando do Departamento de Oftalmologia, Otorrinolaringologia e Cirurgia de Cabeça e Pescoço pela Faculdade de Medicina da Universidade de São Paulo USP - Ribeirão Preto (SP) - Brasil.

Professor Titular do Departamento de Oftalmologia, Otorrinolaringologia e Cirurgia de Cabeça e Pescoço da USP - Ribeirão Preto (SP) - Brasil.

Endereço para correspondência: Rua Feijó Júnior, 975/403 - Caxias do Sul (RS) CEP 95064-160 E-mail: marciocostanzi@bol.com.br

Recebido para publicação em 26.09.2005 Última versão revisada recebida em 14.03.2007 Aprovação em 26.03.2007

Nota Editorial: Depois de concluída a análise do artigo sob sigilo editorial e com a anuência do Dr. José Vital Filho sobre a divulgação de seu nome como revisor, agradecemos sua participação neste processo.

\section{RESUMO}

A displasia fibrosa é considerada uma desordem óssea benigna, de progressão lenta na qual há substituição de osso normal por tecido fibroso Quando associada a hiperpigmentação de pele e distúrbios endocrinológicos denomina-se síndrome de McCune Albright. Relatamos um caso raro de síndrome de McCune Albright em uma criança do sexo masculino que apesar de apresentar mínimas distorções crânio-facial externas, mostrou um envolvimento difuso e bilateral das órbitas.

Descritores: Displasia fibrosa poliostótica/diagnóstico; Doenças orbitárias; Anormalidades craniofaciais; Ossos faciais/anormalidades

\section{INTRODUĈ̃̃}

Em 1891, von Recklinghausen descreveu pacientes com condições patológicas ósseas caracterizadas pela presença de deformidades e alterações fibrosas, denominando essa condição de "osteites fibrosa generalisata". Só quatro décadas depois é que Liechtenstein e Jaffe reconheceram, em 1938, a condição descrita por von Recklinghausen como uma entidade nosológica bem delineada e a nomearam displasia fibrosa $(\mathrm{DF})^{(1)}$.

A DF é uma desordem displásica do osso, caracterizada por proliferações de fibroblastos fusiformes entremeados por trabéculas de tecido ósseo imaturo não rodeados por osteoblastos ${ }^{(2)}$.

A doença é considerada uma desordem óssea benigna, de progressão lenta, na qual há substituição de osso normal por tecido fibroso. Em geral afeta 1 em cada 4.000 a 10.000 indivíduos. Trata-se de um distúrbio não familiar, congênito, que produz cerca de $2,5 \%$ de todos os tumores ósseos e mais de $7 \%$ de todos os tumores não malignos do osso $^{(3)}$.

A displasia fibrosa pode se apresentar de forma isolada ou associada às manifestações extra-esqueléticas. Dessas, a mais comum é a presença de manchas hiperpigmentadas do tipo "café-com-leite". Quando além dessas manchas, a DF é também acompanhada de distúrbios endócrinos, a tríade é denominada de síndrome de McCune Albright. Essa doença, descrita pela primeira vez em 1937, é bem mais rara que a forma isolada da DF e, usualmente ocorre em crianças do sexo feminino ${ }^{(1,3)}$.

O objetivo do presente trabalho é relatar um caso raro de síndrome de McCune Albright em uma criança do sexo masculino que, apesar de apresentar mínimas distorções craniofaciais externas, mostrou um envolvimento difuso e bilateral das órbitas. 


\section{RELATO DE CASO}

Criança do sexo masculino, 7 anos de idade foi atendida no Hospital das Clínicas de Ribeirão Preto aos 2 anos de idade apresentando fratura no membro inferior. O exame radiológico evidenciou áreas de displasia fibrosa e clinicamente observouse manchas café-com-leite em face. Três anos após a fratura desenvolveu puberdade precoce, sendo então feito o diagnóstico de síndrome de McCune Albright. Encaminhado ao serviço de Oftalmologia para avaliação o paciente. Ao exame notou-se retração palpebral inferior (distância da margem palpebral inferior ao centro pupilar de $7,0 \mathrm{~mm}$ em ambos os olhos), fenda palpebral com orientação anti-mongolóide e presença de discreto abaulamento da região frontal (Figura 1). A acuidade visual era $1,0 \mathrm{em}$ ambos os olhos, o campo visual era normal, a exoftalmometria era de $13 \mathrm{~mm}$ (OD) e $14 \mathrm{~mm}$ (OE), fundoscopia e oculomotricidade sem alterações.

Apesar da relativa normalidade do exame oftalmológico, uma tomografia computadorizada de crânio e face foi solicitada, cujo resultado revelou importante comprometimento orbitário circunferencial bilateral englobando todas as paredes orbitárias, inclusive as regiões apicais (Figura 2).

\section{COMENTÁRIOS}

A DF não é tratável medicamente. Na área craniofacial, o único tratamento possível é a correção cirúrgica das distorções ósseas que induzem problemas do tipo distopias oculares,

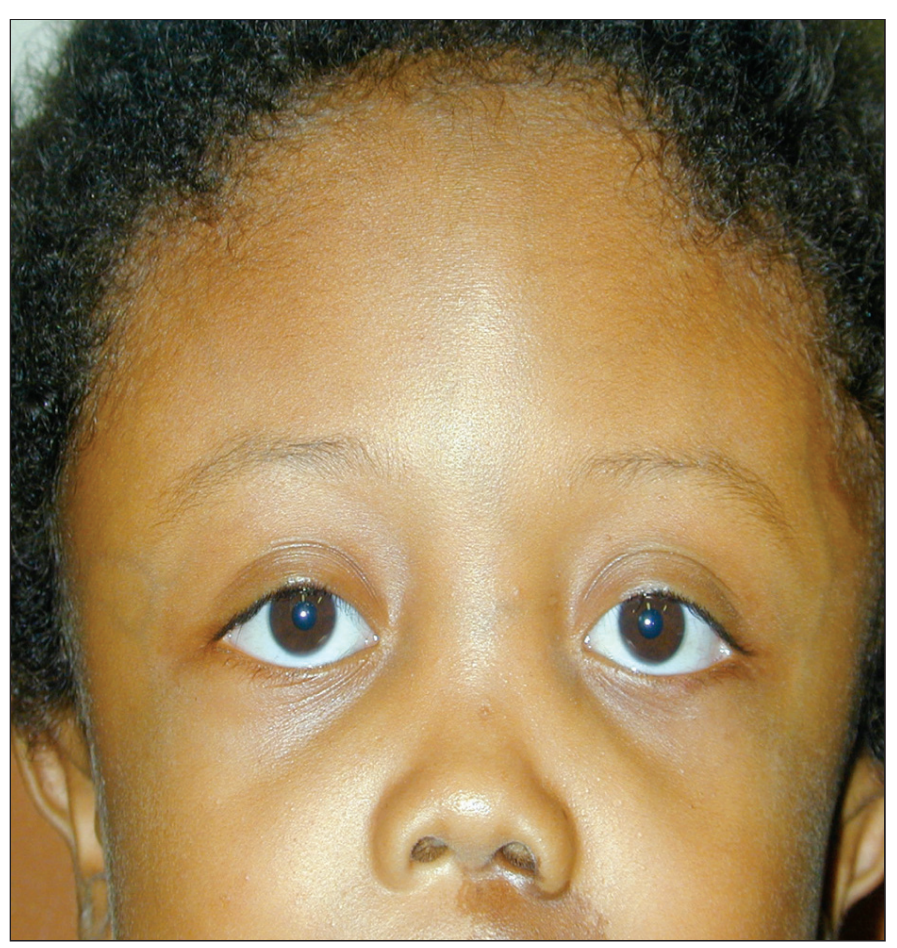

Figura 1 - Criança com 7 anos de idade portadora da síndrome de McCune Albright

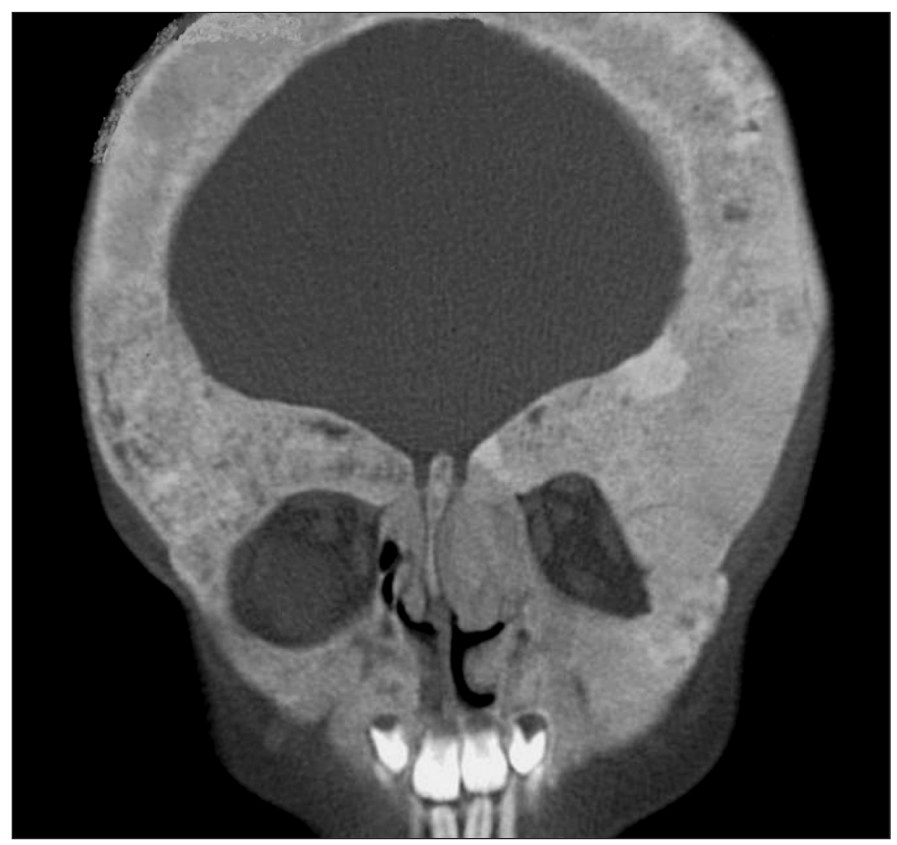

Figura 2-Tomografia computadorizada evidenciando comprometimento orbitário bilateral

abaulamentos e proptose. Quando há comprometimento do ápice orbitário existe a possibilidade de envolvimento do forame óptico e fissura orbitária superior e conseqüente compressão das estruturas neurovasculares que transitam por essas aberturas ósseas (nervo óptico, artéria oftálmica, nervos cranianos III, IV, V, VI, veia oftálmica superior e ramos simpáticos). Essa compressão pode levar à perda de campo visual e mesmo amaurose.

Nesse contexto, poder-se-ia propor procedimentos cirúrgicos descompressivos que prevenissem eventuais compressões ópticas. O problema é que as cirurgias de descompressão do canal óptico na DF são extremamente perigosas e há relatos de caso de amaurose após esse tipo de procedimento ${ }^{(4)}$. Por outro lado é comum, como no caso em questão, haver uma grande dissociação entre o quadro radiológico e o clínico.

Os oftalmologistas que tratam pacientes com DF precisam entender que o tecido anormal, evidenciado radiologicamente com aspecto de "vidro fosco" não é, necessariamente, pétreo, mas sim fibroso, o que explica a manutenção das funções visuais por longos períodos de tempo, ou mesmo, toda a vida, apesar da gravidade do quadro radiológico. No caso em questão optamos por uma conduta expectante com avaliações seriadas da função visual.

A tomografia computadorizada de crânio e face, de preferência com janela óssea, é sempre necessária para a avaliação de pacientes com DF, mesmo nos casos que aparentemente não apresentam grandes acometimentos orbitários.

\section{ABSTRACT}

Fibrous dysplasia is a benign, slowly progressive bone disor- 
der, in which normal bone is replaced by fibrous tissue. It is called McCune Albright syndrome when associated with skin hyperpigmentation and endocrinological disorders. We report a rare case of McCune Albright syndrome in a boy, who presented bilateral and diffuse involvement of orbits but few external craniofacial distortions.

Keywords: Fibrous dysplasia, polyostotic/diagnosis; Orbital diseases; Craniofacial abnormalities; Facial bones/abnormalities

\section{REFERÊNCIAS}

1. Ricalde P, Horswell BB. Craniofacial fibrous dysplasia of the fronto-orbital region: a case series and literature review. J Oral Maxillofac Surg. 2001; 59(2): 157-67; discussion 167-8.

2. Selva D, White VA, O'Connell JX, Rootman J. Primary bone tumors of the orbit. Surv Ophthalmol. 2004;49(3):328-42.

3. Edgerton MT, Persing JA, Jane JA. The surgical treatment of fibrous dysplasia. With emphasis on recent contributions from cranio-maxillo-facial surgery. Ann Surg. 1985;202(4):459-79.

4. Edelstein C, Goldberg RA, Rubino G. Unilateral blindness after ipsilateral prophylactic transcranial optic canal decompression for fibrous dysplasia. Am J Ophthalmol. 1998;126(3):469-71. 